\title{
Fabrication and characterization of magnetic FePt nanoparticles prepared by extraction-pyrolysis method
}

V. Serga ${ }^{1}$,

M. Maiorov' ${ }^{2}$,

A. Cvetkovs ${ }^{1}$,

A. Krumina ${ }^{1}$,

A. I. Popov ${ }^{3,4^{*}}$

${ }^{1}$ Institute of Inorganic Chemistry,

Riga Technical University,

7 Paula Valdena, Riga, 1048, Latvia

${ }^{2}$ Institute of Physics,

University of Latvia,

32 Miera, Salaspils, 2169, Latvia

${ }^{3}$ Institute of Solid State Physics, University of Latvia, 8 Kengaraga,

Riga, 1063, Latvia

${ }^{4}$ Institut Laue-Langevin,

Grenoble 38000, France
In the present work, possibilities of the extraction-pyrolysis method (EPM) to produce FePt nanoparticles with the face-centered tetragonal (fct) phase were studied. A mixture of fine-disperse powder of carbonyl iron and n-trioctylammonium hexachloroplatinate $\left[\left(\mathrm{C}_{8} \mathrm{H}_{17}\right)_{3} \mathrm{NH}\right]_{2} \mathrm{PtCl}_{6}$ solution in toluene, preliminary produced by the solvent extraction method, is used as a precursor. Precursors with a different molar ratio of metals were used. The performed investigations show that as a result of pyrolysis in the air $\left(T_{\mathrm{pyr}}=600^{\circ} \mathrm{C}, t_{\text {anneal }}=30 \mathrm{~min}\right)$, a FePt alloy with the fct phase is produced. Moreover, such phases as $\mathrm{FePt}_{3}$ and/or $\mathrm{Fe}_{3} \mathrm{Pt}$ with the cubic structure may be also present in the final products. The phase composition of the produced samples depends on the Fe:Pt molar ratio in the precursor. An increase of the fct phase part with the growth of the iron content from 40 to $60 \mathrm{~mol} \%$ is observed. Also, with the Fe80\%Pt $20 \%$ molar ratio of the metals in the precursor, only the ordered fct phase along with a small amount of hematite and iron chloride exists in the produced sample. Magnetic measurements confirm the fct-FePt phase formation in all produced samples and evidence that the coercivity exceeds the value ( $3 \mathrm{kOe}$ ) at the $50 \mathrm{~mol} \% \mathrm{Fe}$ concentration in the precursor and significantly decreases with increasing the Fe concentration to $80 \mathrm{~mol} \%$.

Keywords: FePt alloy, extraction-pyrolysis method, Fe/Pt composition, high magnetic coercivity

\section{INTRODUCTION}

The magnetic materials with high coercivity $H_{c}$ can be valuable for a great number of advanced applications. These materials can be used in powerful permanent magnets, information storing devices of high density. Moreover, nanoparticles of such materials can be used for ferrofluids with special properties. One of the promising materials are the FePt alloys, which have giant coercivity, high corrosion resistance and therefore have been the subject of extensive studies since last 15 years [1-29]. Various preparation techniques are used to produce the FePt nanoparticles with

* Corresponding author. Email: popov@ill.fr; popov@latnet.lv the ordered face-center-tetragonal (fct) structure. Typically, the synthesis starts with the preparation of nanoparticles with the face-center-cubic (fcc) structure followed by annealing at higher temperatures for the transformation to the fct structure. Solution phase chemical decomposition of iron pentacarbonyl $\mathrm{Fe}(\mathrm{CO})_{5}$ and reduction of platinum acetylacetonate $\mathrm{Pt}(\mathrm{acac})_{2}$ are the mostly used methods to produce the FePt nanoparticles [22-25]. The method allows to produce small particles $(<10 \mathrm{~nm})$ with the cubic structure. However, after the thermal treatment of as-prepared FePt nanoparticles, an increase of the particle size is observed. To prevent the particles from sintering at high annealing temperatures, the use of $\mathrm{NaCl}$ salt as a separation medium [26] or the coating of the as-prepared fcc-FePt 
nanoparticles with $\mathrm{MgO}$ before thermal treatment 27] is proposed. The coercivity value for the produced samples varied from 15 to 30 and $10 \mathrm{kOe}$, respectively.

The use of solid-phase synthesis - high energy ball milling shows [28] that the method allows to produce fcc FePt with particle sizes of around $10 \mu \mathrm{m}$ with a broad distribution of the particle size. The following thermal treatment is necessary for the phase transformation to the fct phase. The $H_{c}$ value of the final product was $2.5 \mathrm{kOe}$.

The plasma-induced cathodic discharge electrolysis in a molten salt electrolyte without post-annealing is proposed in [29]. By utilizing co-deposition of metals, a FePt alloy with a particle size about $50 \mathrm{~nm}$ and $H_{c}$ about $3 \mathrm{kOe}$ was produced. However, both the ordered and the disordered phases coexist in the final products. The same results were obtained via co-reduction of iron acetylacetonate $\mathrm{Fe}(\mathrm{acac})_{3}$ and $\mathrm{Pt}(\mathrm{acac})_{2}$ in tetraethylene glycol, but the average size of the produced particles was smaller (about $5 \mathrm{~nm}$ ) [21, 30] and the coercivity value was $2.1 \mathrm{kOe}$ [21].

The ordered fct-FePt nanoparticles with a mean diameter of $14 \mathrm{~nm}$ and $H_{c}$ about $10 \mathrm{kOe}$ were successfully synthesized by using the sol-gel method [31].

It must be emphasized that for all the above-mentioned methods to prevent iron oxidation the heat treatment was carried out in an inert atmosphere. So if the as-prepared chemically disordered $\mathrm{FePt}$ samples are annealed in the presence of oxygen, such phases as $\mathrm{FePt}_{3}, \mathrm{Fe}_{3} \mathrm{O}_{4}, \mathrm{a}-\mathrm{Fe}_{2} \mathrm{O}_{3}$ and $P t$ are obtained [25].

In recent years, the extraction-pyrolysis method (EPM) has been successfully used to synthesize various functional materials [32]. This method provides the use of extractive systems for the production of oxide materials of various applications. The main advantages of this method are simplicity and low costs and it can be applied without sophisticated equipment. In previous papers [33-39], we have successfully used the EPM to produce nanopowders of cobalt, nickel ferrites, platinum nanoparticles on the carrier, $\mathrm{MgO}$ nanoparticles, $\mathrm{ZnO}, \mathrm{ZnO}-\mathrm{CdO}$ thin films and some others. In the present work, some possibilities of the EPM for the production of FePt nanoparticles with the fct phase were studied.

\section{EXPERIMENTAL}

In order to produce a FePt alloy by the EPM, a Pt-containing organic extract was preliminary prepared by solvent extraction. A solution of n-trioctylamine $\left(\mathrm{C}_{8} \mathrm{H}_{17}\right)_{3} \mathrm{~N}$ in toluene was used as an extractant. The procedure of extract preparation is described in detail in [35]. Then a weight of finedisperse commercial iron powder (R-10 type carbonyl iron) was added to the Pt-containing extract, namely, a n-trioctylammonium hexachloroplatinate $\left[\left(\mathrm{C}_{8} \mathrm{H}_{17}\right)_{3} \mathrm{NH}\right]_{2} \mathrm{PtCl}_{6}$ solution in toluene $\left(\mathrm{C}_{\mathrm{Pt}}=0.4 \mathrm{M}, \mathrm{V}=1.28 \mathrm{ml}\right)$. This mixture was used as the precursor. The iron content in the precursor was varied from 40 to $80 \mathrm{~mol} \%$. The precursor was heat- ed from room temperature up to $600^{\circ} \mathrm{C}$ and annealed for $30 \mathrm{~min}$ in air.

The phase composition of the pyrolysis products was defined by the X-ray diffraction method using a diffractometer D8 Advance (Bruker Corporation) with $\mathrm{CuK}_{\alpha}$ radiation $(\lambda=1.5418 \AA)$. The XRD patterns were referenced to the PDF ICDD 043-1359 for fct-FePt identification, to PDF ICCD 071-8364 and PDF ICCD 071-5031 for $\mathrm{Fe}_{3} \mathrm{Pt}_{\text {and }} \mathrm{FePt}_{3}$ identification, respectively.

The mean crystallite size of fct-FePt in the produced samples was defined from the (111) peak width by the Scherrer method.

Magnetic measurements were made at room temperature by a vibration magnetometer (Lake Shore Cryotronic 7404 ) in a magnetic field up to 11500 Oe.

SEM measurements were made using the Tescan Lyra-3 which was equipped with an Energy Dispersive Spectrometer (EDS) for composition analysis.

\section{RESULTS AND DISCUSSION}

$\mathrm{X}$-ray diffraction has shown that the commercial product is single-phased and the mean size of iron crystallites is about $9 \mathrm{~nm}$ (see Fig. 1). The magnetic measurements revealed no hysteresis for iron, and the value of saturation magnetization $(\sigma=203 \mathrm{emu} / \mathrm{g})$ was close to that of bulk iron [40].

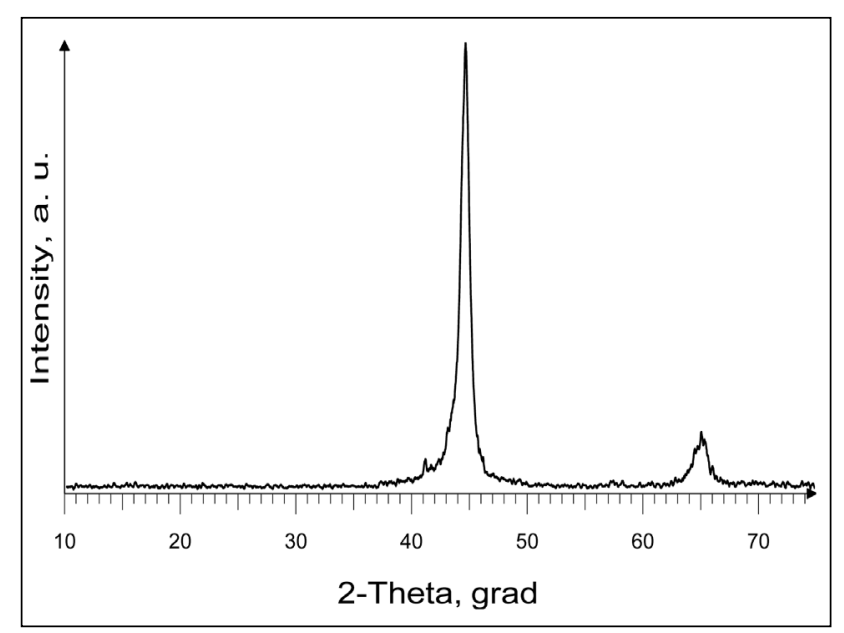

Fig. 1. XRD pattern of the carbonyl iron powder

The XRD data analysis showed (Fig. 2) that the thermal treatment of the iron powder and Pt-containing extract mixture resulted in the formation of a FePt alloy with the combination of fct and fcc phases and a small amount of admixture phases. However, the obtained results do not allow to conclude which cubic phase is present in the samples. No peaks of crystalline platinum and iron were observed.

The phase composition of the final products depends on the Fe:Pt molar ratio in the initial mixture. The increase of 


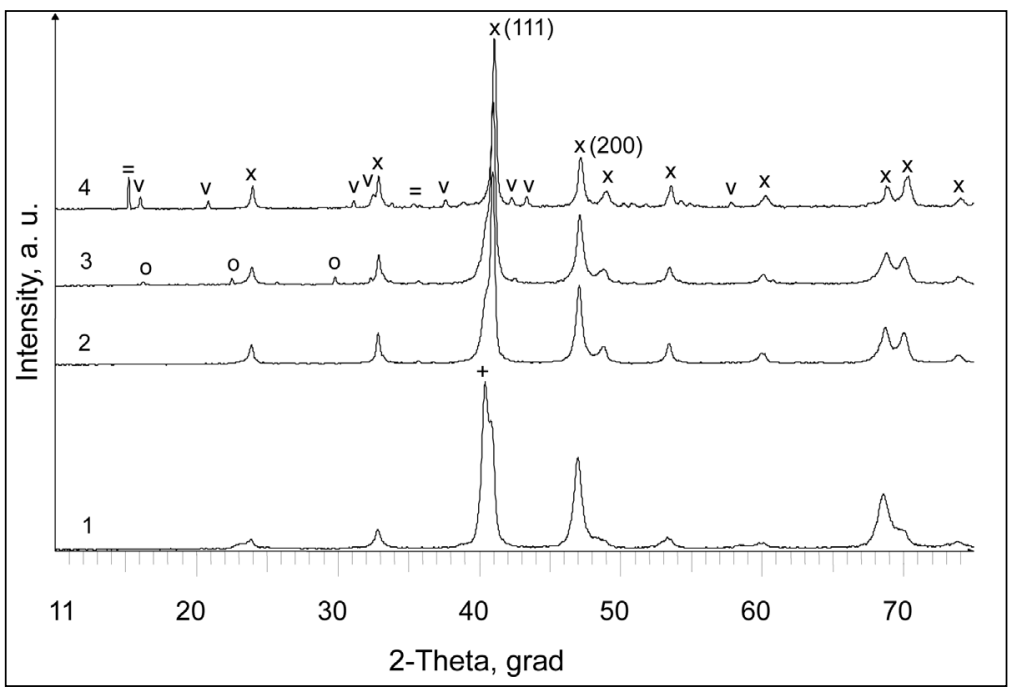

Fig. 2. XRD patterns of the samples produced from different Fe/Pt compositions (mol\%): 1, Fe40\%Pt60\%; 2, Fe50\%Pt50\%; 3, Fe60\%Pt40\%; 4, Fe80\%Pt20\%. (x), fct FePt; (+), FePt and/or $\mathrm{Fe}_{3} \mathrm{Pt} ;(=) \mathrm{FeCl}_{2} ;(\mathrm{v}), \mathrm{FeCl}_{2} \cdot 2 \mathrm{H}_{2} \mathrm{O} ;(0), \mathrm{FeCl}_{2} \cdot 4 \mathrm{H}_{2} \mathrm{O}$

the fct phase part with the growth of the iron content from 40 to $60 \mathrm{~mol} \%$ was observed. Moreover, with the molar ratio of the metals in the precursor being Fe80\%Pt20\%, only the fct phase existed (Fig. 2, Curve 4). The samples produced from the precursors with the iron content $\geq 50 \mathrm{~mol} \%$ contained only a small amount of the iron oxidation product - hematite $\left(\mathrm{a}-\mathrm{Fe}_{2} \mathrm{O}_{3}\right)$. Additionally, as a result of the chemical reaction of iron with hydrochloric acid and water, at the thermal decomposition of the Pt-containing extract, iron (II) chloride, iron (II) chloride di- or tetrahydrate appeared with the iron content increase. The admixture phases were not observed with the $40 \mathrm{~mol} \%$ iron content in the precursor (Fig. 2, Curve 1).
With reference to the XRD data, the mean crystallite size of fct-FePt in the produced samples varies from 15 to $30 \mathrm{~nm}$.

The magnetic hysteresis loops of the above-mentioned samples are presented in Fig. 3. Because of giant coercivity the obtained loops are off-peek loops, i.e. the magnetic field value of magnetization and demagnetization lines closure is higher than the given value of the maximum field. Therefore, the obtained coercivity values are less than the actual values. Indeed, the maximum coercivity value was about $3 \mathrm{kOe}$, however, it is known [26] that the thermal annealing of the synthesized FePt nanoparticles converts the fcc$\mathrm{FePt}$ to the fct-FePt, yielding nanocrystalline magnets with

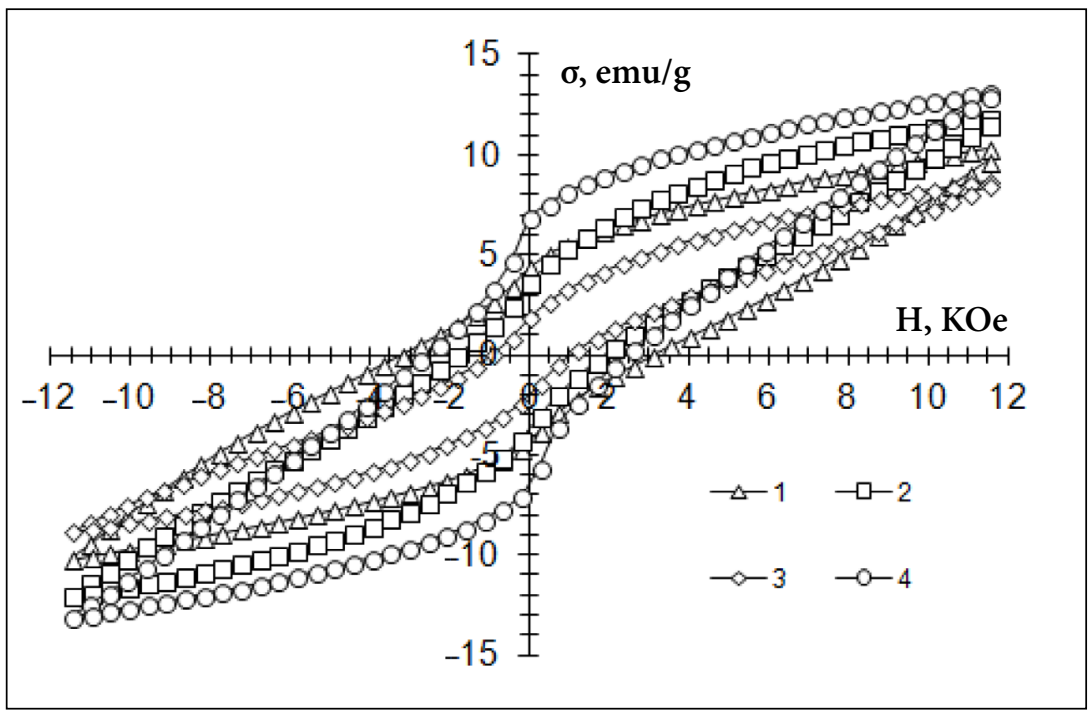

Fig. 3. Hysteresis loops of the samples produced from different Fe/Pt compositions (mol\%): 1, Fe50\%Pt50\%; 2, Fe60\%Pt40\%; 3, Fe80\%Pt20\%; 4, Fe40\%Pt60\% 
the coercivity as high as $30 \mathrm{kOe}$. In spite of this fact, we will use the obtained magnetic data to compare the samples.

The variations of the coercivity $H_{c}$ relative to the molar iron-platinum ratio in the precursor are illustrated in Fig. A. From the presented data it is seen that the samples prepared from the $\mathrm{Fe} 40 \% \mathrm{Pt} 60 \%$ and Fe $50 \% \mathrm{Pt} 50 \%$ compositions have the highest coercivity. However, according to the XRD analysis data, only these products contain a significant amount of the cubic phase (Fig. 2, Curves 1,2). Probably, this is due to the presence of the $\mathrm{Fe}_{3} \mathrm{Pt}$ phase, which contributes to the magnetic properties of the samples.

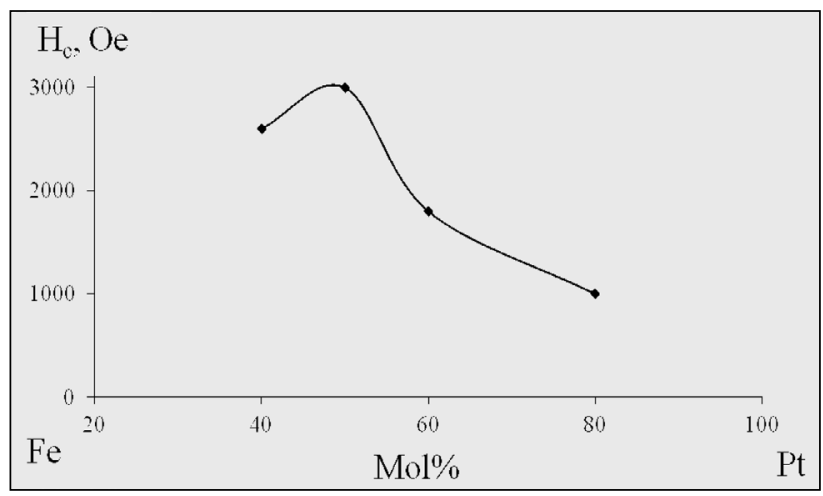

Fig. 4. Coercivity versus the Fe/Pt molar ratio in the precursor

To perform microscopy investigations, a sample of the FePt nanopowder produced from the Fe $80 \% \mathrm{Pt} 20 \%$ precursor composition was used. Due to the XRD phase analysis data (Fig. 2. Curve 4), along with the basic fct-FePt phase the sample contains only iron chloride (II) as an admixture phase. Therefore, to remove the admixture, the powder sample was preliminary treble washed first with distilled water, then with acetone and finally dried at room temperature.

Finally, the SEM micrograph (Fig. B) presents platinumcoated spherical particles of 100 to $400 \mathrm{~nm}$ in diameter with

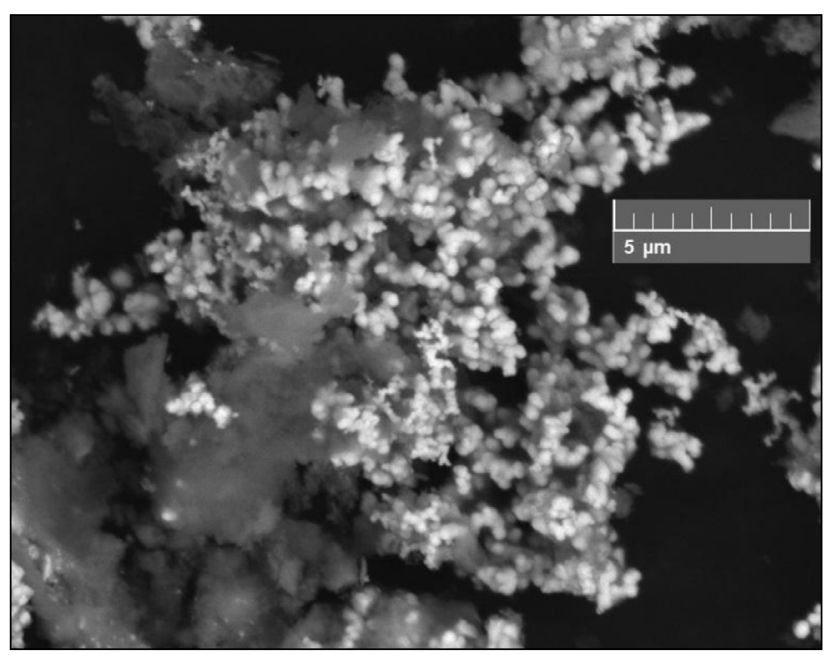

Fig. 5. SEM micrograph of the FePt nanopowder a stronger contrast and large shapeless agglomerates sized of 1-4 $\mu \mathrm{m}$, which was observed with a weaker contrast.

\section{CONCLUSIONS}

The performed investigations have revealed that the EPM makes it possible to produce the FePt nanoparticles with the fct phase. The phase composition of the final products depends on the Fe:Pt molar ratio in the precursor. The $\mathrm{FePt}_{3}$ and/or $\mathrm{Fe}_{3} \mathrm{Pt}$ phases are present in the produced samples along with the fct-FePt phase, with the iron content in the precursor varying from 40 to $60 \mathrm{~mol} \%$. The maximum coercivity (no less than $3 \mathrm{kOe}$ ) has the nanopowder prepared from the precursor with the Fe $50 \% \mathrm{Pt} 50 \%$ metal composition.

\section{ACKNOWLEDGEMENTS}

We are grateful to Prof. E. Kotomin for useful discussions. The research leading to these results has received funding from the ERAF (2017) Project, while A. I. Popov thanks IMIS-2 for the funding support.

Received 16 January 2018 Accepted 15 February 2018

\section{References}

1. P. Jang, C. S. Jung, K. Seomoon, K. H. Kim, Curr. Appl. Phys., 11(4), S95 (2011).

2. J. S. Noh, H. Kim, D. W. Chun, W. Y. Jeong, W. Lee, Curr. Appl. Phys., 11(4), S33 (2011).

3. J. K. Tsai, T. L. Wu, S. M. Chao, et al., Ferroelectr., 421(1), 43 (2011).

4. I. Khan, J. Hong, Comput. Mater. Sci., 117, 527 (2016).

5. Z. Guo, X. Yang, J. Deng, et al., J. Alloys Compd., 687, 204 (2016).

6. Z. Bamshad, S. A. Sebt, M. R. Abolhassani, J. Supercond. Nov. Magn., 29, 3139 (2016).

7. S. Schneider, D. Pohl, S. Löffler, et al., Ultramicroscopy, 171, 186 (2016).

8. A. Fardi-Ilkhchy, F. Nasirpouri, C. Bran, M. Vázquez, J. Solid State Chem., 244, 35 (2016).

9. Z. G. Qiu, D. C. Zeng, L. Z. Zhao, et al., Phys. Rev. B: Condens. Matter., 500, 111 (2016).

10. C. Y. Shen, H. W. Chang, F. T. Yuan, et al., J. Phys. Chem. Solids, 98, 143 (2016).

11. J. Y. Deng, K. F. Dong, Y. G. Peng, et al., J. Magn. Magn. Mater., 417, 203 (2016).

12. S. Chen, S. L. Lee, P. André, J. Magn. Magn. Mater., 417, 442 (2016).

13. T. Hasegawa, T. Yamazaki, S. Ishio, Mater. Lett., 178, 243 (2016).

14. D. J. Carnevale, M. Shatruk, G. F. Strouse, Chem. Mater., 28(15), 5480 (2016).

15. R. Goyal, N. Arora, A. Kapoor, S. Lamba, S. Annapoorni, J. Alloys. Compd., 695, 1014 (2017). 
16. S. A. Khan, J. Minár, H. Ebert, P. Blaha, O. Šipr, Phys. Rev. $B$, 95, 014408 (2017).

17. J. G. Ovejero, V. Velasco, F. M. Abel, et al., Mater. Des., 113, 391 (2017).

18. S. Pramchu, A. Punya, Y. Laosiritaworn, Integr. Ferroelectr., 175(1), 255 (2016).

19. X. Zhang, F. Xiong, X. Jiang, Z. Hua, C. Wang, S. Yang, Appl. Phys. Lett., 109, 243106 (2016).

20. R. Goyal, N. Sehdev, S. Lamba, S. Annapoorni, Solid State Commun., 226, 44 (2016).

21. K. Sato, B. Jeyadevan, K. Tohji, J. Magn. Magn. Mater., 289, 1 (2005).

22. S. Sun, C. B. Murray, D. Weller, L. Folks, A. Moser, Science, 287(5460), 1989 (2000).

23. M. Chen, J. Kim, J. P. Liu, H. Fan, S. Sun, JACS, 128(22), 7132 (2006).

24. L. Colak, G. C. Hadjipanayis, Nanotechnology, 20(48), 485602 (2009).

25. C. Liu, T. J. Klemmer, N. Shukla, et al., J. Magn. Magn. Mater., 266(1), 96 (2003).

26. K. Elkins, D. Li, N. Poudyal, V. Nandwana, Z. Jin, K. Chen, J. P. Liu, J. Phys. D: Appl. Phys., 38(14), 2306 (2005).

27. J. Kim, C. Rong, J. P. Liu, S. Sun, Adv. Mater., 21(8), 906 (2009).

28. V. Velasco, A. Martinez, J. Recio, A. Hernando, P. Crespo, J. Alloys Compd., 536, S13 (2012).

29. M. Tokushige, T. Nishikiori, M. C. Lafouresse, et al., Electrochim. Acta, 55(27), 8154 (2010).

30. Y. Kitamoto, J.-S. He, Electrochim. Acta, 54, 5969 (2009).

31. Y. Liu, Y. Jiang, X. Zhang, et al., Powder Technology, 239, 217 (2013).

32. A. I. Kholkin, T. N. Patrusheva, Theor. Found. Chem. Eng., 50, 785 (2016).
33. V. Serga, M. Maiorov, A. Petrov, A. Krumina, Integr. Ferroelect., 103, 18 (2009).

34. V. Serga, L. Kulikova, M. Maiorov, A. Krumina, Latv. J. Chem., 50, 32 (2011).

35. E. Palcevskis, L. Kulikova, V. Serga, et al., J. Serb. Soc., 77, 1799 (2012).

36. A. I. Popov, L. Shirmane, V. Pankratov, et al., Nucl. Instrum. Methods B, 310, 23 (2013).

37. S. Chornaja, K. Dubencov, V. Kampars, et al., React. Kinet., Mech. Catal., 108, 341 (2013).

38. I. Ivanov, P. Petrova, V. Georgiev, et al., Catal. Lett., 143, 942 (2013).

39. S. Chornaja, S. Zhizhkun, K. Dubencov, et al., Chemija, 26, 113 (2015).

40. I. I. Kikoin (ed.), Tables of Physical Quantities, Reference Book, Atomizdat, Moscow (1976).

V. Serga, M. Maiorov, A. Cvetkovs, A. Krumina, A. I. Popov

\section{MAGNETINIŲ FePt NANODALELIŲ, GAUTŲ EKSTRAKCIJOS-PIROLIZĖS BŪDU, GAVIMAS IR APIBŪDINIMAS}

Santrauka

Darbe tirtos FePt nanodaleliu gavimo ekstrakcijos-pirolizès metodu galimybès. Reakcijos pirmtaku naudoti susmulkinti geležies karbonilo milteliai ir n-trioktilamonio heksachlorplatinato $\left[\left(\mathrm{C}_{8} \mathrm{H}_{17}\right)_{3} \mathrm{NH}\right]_{2} \mathrm{PtCl}_{6}$ tirpalas toluene, gautas skystinès ekstrakcijos būdu. Pirolizès būdu ore $600{ }^{\circ} \mathrm{C}$ temperatūroje per $30 \mathrm{~min}$. gaunamas FePt lydinys. 
